\title{
KEYNES AND HARROD ON THE CLASSICAL THEORY OF INTEREST: MORE ON THE ORIGIN OF THE ONLY DIAGRAM IN THE GENERAL THEORY
}

\author{
BY
}

\section{DANIELE BESOMI}

\begin{abstract}
"You will understand that my task is to state what Maynard actually held, not whether he was right or wrong."

(Harrod to Hawtrey, June 7, 1951, with reference to Harrod 1951).
\end{abstract}

\section{INTRODUCTION}

Rod O'Donnell's (1999a, 1999b) and James Ahiakpor's (1999) contribution s on the origin of the only diagram in J. M. Keynes's General Theory raise some interesting points regarding the use of documentary evidence for interpreting authors' ideas or specific passages in their writings.

O'Donnell argues that a careful reading of the correspondence between Keynes and Roy Harrod regarding the figure on p. 180 of the General Theory considerably weakens Harrod's later claim (accepted and reproduced by other authors) that he "supplied" the diagram (Harrod 1951, p. 453), and suggests instead (with high probability) that the actual drawing was authored by Keynes himself, following Harrod's detailed instructions. The episode is, of course, a marginal one in the history of economic ideas. Nevertheless, its implications are of a certain importance as to the relative weight that historians should attribute to contemporary and subsequent sources.

In section II below, some supplementary evidence supporting O'Donnell's

Daniele Besomi, independent researcher, c.p. 7, 6950 Gola di Lago, Switzerland, dbesomi@ cscs.ch. A preliminary draft was read by James Ahiakpor (whom I have failed to convince) and Rod O'Donnell (who was convinced already). Their comments nonetheless considerably helped improving the paper, although the responsibility for remaining mistakes entirely falls on myself.

I am indebted to the librarians who granted me access to the collections they take care of (these are listed in note 4 and in the References). I am also grateful to Chiba University of Commerce for permission to cite from Harrod's papers in their possession, to Lady Harrod and Dominik Harrod for permission to cite from the remainder of Harrod's writings. This paper was written while benefiting from a research grant, which is gratefully acknowledged, offered by the Department of Education and Culture, Ticino Canton, Switzerland, for the preparation of an edition of the Inter-War Papers and Correspondence of Roy Harrod; some preliminary work was supported by the Italian Ministry of University and Scientific Research as part of the research project "Conceptual innovations in economics: a contextualized analysis of the contribution made by the Cambridge economists." 
claim is provided, based on Harrod's style of writing and on his attitude towards the preservation of documents for posterity. In section III, the origin of the diagram is examined in its context, showing that Keynes reinterpreted Harrod's instructions, inverted the causal nexuses represented in the diagram, added a demand curve, and used it to argue against Harrod's point. In the concluding section Harrod's claim that he supplied the diagram is examined in light of the changed conditions between the time of commenting upon the proofs of the General Theory and writing his Life of Keynes.

\section{SUPPLEMENTARY EVIDENCE}

I fundamentally agree with O'Donnell's conclusion and can only add some consideration s based on Harrod's style and on the materials preserved among his papers.

O'Donnell rightly points out that if Harrod actually drew the diagram, a reference to this would be likely to be found somewhere. It is well known that Keynes "was a shocking hoarder" (Harrod to Macmillan, April 21, 1948), and accordingly, in the archives at King's College in Cambridge, most runs of correspondence are complete (O'Donnell 1999b, p. 46). This specific exchange with Harrod also is otherwise complete, but a diagram by Harrod does not appear to be among Keynes's papers. This is where we should expect it to be in the first place, as Keynes stated that he was sending a transcription of the note back to Harrod but did not mention the diagram which, if it ever was sent, was not returned.

Nevertheless, if the diagram was sent back to Harrod, and if Harrod withdrew it from the Keynes papers, ${ }^{1}$ or if a draft was drawn by him, he would most certainly have preserved it, as he was even more meticulous than Keynes in collecting his papers - those he viewed as "of some interest for the history of economic thought" ${ }^{2}$ he himself classified, labeled, and commented upon for the benefit of future researchers. ${ }^{3}$ The diagram, however, is not extant in any of the publicly accessible collections of Harrod papers. ${ }^{4}$ If the diagram was actually drawn by Harrod, he would certainly have come across it while writing the Life of Keynes, when he re-read his correspondence with his friend. In fact, in the

\footnotetext{
${ }^{1}$ Some items that should logically belong to the Keynes papers ended up among the Harrod papers instead.

${ }^{2}$ The passage is drawn from a note dated 1945 describing the correspondence relating to Harrod's discovery of the marginal revenue curve; the episode is accurately reported in an "egoistic footnote" to the Life of Keynes (Harrod 1951, pp. 159-60).

${ }^{3}$ A number of exchanges preserved at Chiba University of Commerce at Ichikawa, Japan, where the most important of the Harrod collections is housed, are labeled with notes describing their subject, and some are commented upon. It is clear that at various stages of his life (not all these notes, unfortunately, are dated) Harrod felt the need to sort out the witness of the intellectual legacy he was bequeathing to posterity.

${ }^{4}$ On Harrod's death his papers were sold in seven separate batches and have ended up on three continents-more precisely, in Japan in the libraries of the Nagoya University of Commerce and Business Administration, Chiba University of Commerce and Tokyo University; in the United States, at the library of Georgetown University in Washington; and in Britain, at the British Library in London (which bought three collections).
} 
very passage in which the diagram is mentioned, Harrod declared that he had the "pile of notes and letters" before him (Harrod 1951, p. 452). This statement is almost certainly correct-in substance, if not literally-as proven by Harrod's accurate lists of the places from which he sent his letters, including his holiday destinations. ${ }^{5}$ Given the emphasis on the diagram, if a drawing by Harrod existed, it would now almost certainly be among Harrod's papers, probably with a note explaining that it was the original of the only diagram in the General Theory.

A different kind of additional element corroborating O'Donnell's conclusion lies in Harrod's use of the word "construction": "By all means use my construction of a family of classical supply curves if you feel so disposed" (Harrod to Keynes, September 20, 1935, in Keynes 1973, p. 560). O'Donnell (1999b, pp. 46-47) points out that the word is ambiguous, as it can indicate either a diagram or instructions on how to draw one. The word itself cannot, therefore, settle the matter. Nevertheless, a closer look at Harrod's terminology in describing diagrams and his use of the word "construction" on other occasions shifts the balance of probabilities in favor of the interpretation that he did not refer to a drawn diagram, but rather to a mental "construction."

I have scanned Harrod's interwar unpublished papers and correspondence looking for both aspects. On the one hand, Harrod never used the word "construction" to unambiguously describe a diagram: often he just drew them (fairly sparingly) and introduced them with expressions such as "it can be drawn thus:-," or he referred to them as "figures" (ten occurrences), or referred to some components as "curves"; he also used the word diagram" (five times), and the word "drawing" (once). On the other hand, the word "construction" is normally used (thirteen out of eighteen occurrences) to unambiguously refer to a theory or model, as for instance in the following sentence: "Now, while it is possible that many or all of his points taken in isolation are not novel, I feel that his [Keynes's] construction regarded as a unity is, that that construction is a remarkable intellectual achievement and likely to serve as a useful tool of thought" (Harrod to Knight, July 7, 1937). In the remaining five occurrences, the word could indicate either an actual drawing or the theoretical specification of the object to be drawn: "cf. my construction of the family of curves and the envelope; a similar construction was also worked out independently by Viner, tho he got an essential detail wrong" (Harrod to Robertson, September 3, 1932). Or: "Meanwhile I became dissatisfied with the article on other grounds and did

\footnotetext{
${ }^{5}$ There are, however, inaccuracies in the order. In the Life, Harrod states that his "comments poured in from Oxford, from London, from St. Ives (Cornwall), from Land's End, and again from London, and again from Oxford" (Harrod 1951, p. 452). The letters were actually sent from London, Oxford (2), London, St. Ives, Land's End (4), London (3). If Harrod's statement were to be taken literally, he did not have the whole run in front of him and at least one letter (the last one from Oxford) has subsequently gone missing-which is unlikely, as there is no internal indication in the letters suggesting that there were other items in the exchange. It is possible that Harrod has listed in the run a letter belonging to the next exchange-reproduced in Keynes (1973, pp. 564-65): in which case the series continues Oxford (2), and London; these letters, however, were stimulated by an entirely unrelated correspondence with Robertson. It is more likely that Harrod had fictionalized his report, along the lines of the process he himself described to Henry Phelps Brown (cited in O'Donnell 1999b, pp. 48-49).
} 
not press for its publication. I scrapped it; and in 1930 wrote quite a different article but embodied in it my original construction of the M.R. curve" (Harrod to J. Robinson, July 1, 1933).

The potential ambiguity arises from the fact that the specific theoretical construction under discussion in these examples takes the form of a diagram. But Harrod seems to refer to the envelope and the marginal revenue curve as concepts, not to their actual diagrams. This is likely also the case with Harrod's "family of classical supply curves:" after all, the structure of Harrod's argument reveals in fact that he was much more interested in the idea that there exists a supply curve for every given level of income, the necessity of which arises from the violation of the ceteris paribus assumption on which he insisted several times during the exchange of correspondence (see for instance Keynes 1973, pp. 531-32, 534, 540, 546, 554 and 560), than in its specific graphical representation.

A further argument in support of O'Donnell's conclusion lies in the fact that in Harrod's interwar correspondence with friends or fellow economists there is no reference at all to the diagram, while he often commented upon, or referred to, his exchanges with Keynes on the proofs of the General Theory. Harrod often deplored Keynes's manners and his unfair approach to the classics as, for instance, in correspondence with Hubert Henderson, Frank Knight, and Dennis Robertson. In his only statement on the influence he exerted on Keynes, Harrod admitted defeat in his attempt to induce Keynes to abandon his criticism of the classical theory of interest: "I share your feeling entirely about his [Keynes's] attacks. I have attacked him for them, but have only succeeded in getting the most offending chapter printed in smaller type as an appendix. I regret them, I feel they will raise un-necessary dust-but there it is, that is his way" (Harrod to Robertson, October 7, 1935).

Understanding how the diagram fits into Harrod's perception of the outcome of his prolonged discussion with Keynes may contribute to explaining why he did not refer to the drawing immediately after publication of the General Theory, while considering it instead as a successful part of his influence after Keynes's death.

\section{THE INTERPRETATION OF THE DIAGRAM}

As O'Donnell pointed out, the suggestion of the diagram took place against the background of Harrod's criticism of Keynes's attack on the theory of interest of the classics. Keynes consistently argued that the saving and investment curves cannot determine the rate of interest as they are not independent of each other, so that shifts in one schedule would imply a movement in the other. He thus insisted that the traditional toolbox is logically flawed, and therefore the theory is nonsense. Harrod admitted that the orthodox view ran into problems as soon as income changed, as it violated the ceteris paribus assumption on which the determination of equilibrium is based, but saw this an inappropriate extension of the domain of application of the traditional tools rather than a flaw in the logic itself of the analytical instrument. While Keynes saw no possibility of reconciliation of his view and orthodoxy, and, therefore, ruthlessly attacked it, Harrod 
maintained that those attacks were unjustified (and tactically inopportune) as the two approaches were compatible, given the appropriate set of assumptions. ${ }^{6}$

Harrod's construction of the family of classical supply curves represented an attempt to "relate the classical supply curve to [Keynes's]" (Harrod to Keynes, August 30, 1935, in Keynes 1973, p. 555; see also Harrod 1951, p. 453). According to Harrod, the classical approach cannot take into account changes in income: instead of having only one curve we must consider a whole family, corresponding to different levels of income.

In his letter of August 30, Harrod provided two equivalent descriptions of the diagram, from which, however, he drew quite distinct conclusions. The first statement runs as follows:

The supply curve of savings and the demand curve for investment have no determinate point of intersection, since they lie along one another throughout their whole length. Certainly: at least on one def. of supply curve of saving. But generally when you draw a supply curve $x=f(y)$, it is assumed that you are treating $x$ as a function of a single variable, price, and other things including income were equal. That is the classical supply curve. To relate the classical supply curve to yours, you would have to draw a family of classical supply curves corresponding to different levels of income and to show that the value of each corresponding to a given rate of interest was identical with that of the demand curve, owing to the operation of the multiplier affecting the level of income. The value $(x)$ of demand for each different value of $y$ (interest) makes (via the multiplier) income such that when you draw the classical supply curve for that level of income (i.e. schedule of saving propensity at various interest rates at that level of income) the value ( $x$ ) of this supply curve for the value of $y$ used in computing that level of income is identical with the value $(x)$ of the demand curve. I have tried to put this in other words again in note at end (Harrod in Keynes 1973, p. 555).

Harrod's premise is that the classical curve is based on the relationship between saving and rate of interest, and thus occupies a two-dimensional space. But, according to Keynes (as interpreted by Harrod, who agreed with the following statement), the main determinant of saving is income. A full representation of the actual state of things would thus require three dimensions, with saving as a function of both the rate of interest and income. The "family of supply curves" is an attempt to reproduce on a plane a three-dimensional diagram, with saving as the dependent variable and the rate of interest and income as its determinants.

The causal relationship between saving, interest, and income Harrod wanted to illustrate was later better expressed in a paper on "Mr. Keynes and Traditional Theory," where Harrod explicitly wrote that "The amount of saving depends not

\footnotetext{
${ }^{6}$ For a more detailed discussion, see Besomi (1997, in particular pp. 99-101). On Harrod's limited understanding of the traditional theory see Marget (1942, pp. 573-80).

${ }^{7}$ It should be noted that this paper was conceived shortly after the exchange with Keynes, as on November 11, 1935, Harrod announced to Robertson the intention of writing it just after the appearance of the General Theory. A first version (no longer extant) was read before the Political Economy Club in Oxford in May 1936, while a second version was read before the Oxford meeting of the Econometric Society on September 26, 1936. A slightly revised version later appeared in Econometrica.
} 
only on the rate of interest, but on the level of income in the community," and that "Keynes is inclined to let the rate of interest drop out of sight" for the sake of brevity only. In Harrod's view, "The justification for this procedure is that [...] the relation of the amount which people choose to save to the rate of interest is a matter of controversy. Moreover, in Mr. Keynes' "view the level of income has a more important effect on the amount which people choose to save than the rate of interest." According to Harrod, "The rate of interest may be brought back into this part of the picture without affecting the main argument" (Harrod 1937, pp. 77-78).

Keynes does not seem to have agreed with this surreptitious re-introduction of the rate of interest as a determinant of saving: besides having stressed in several passages in the correspondence with Harrod that saving and investment do not relate to the same variables (Keynes 1973, pp. 552-53; see also pp. 541 and 551), when he came to revise the relevant passages in the General Theory he specified: "I ... would not deny that the rate of interest may perhaps have an influence (though perhaps not of the kind which they [the classics] suppose) the amount saved out of a given income" (Keynes 1936, p. 178; Keynes's emphasis).

Harrod's construction takes account of the causal relationship s Harrod himself depicted earlier in the same letter (Keynes 1973, p. 553), of which Keynes approved (Keynes 1973, p. 557). Therefore, when Harrod concluded that the diagram drawn following his detailed instruction s would show that, for the level of income corresponding to a given rate of interest, saving is identical to investment, Keynes could not but approve:

All these points of agreement can be summed up in a proposition which the classical school would accept and I would not dispute; namely, that, if the level of income is assumed to be given, we can infer that the current rate of interest must lie at the point where the demand curve for capital corresponding to different rates of interest cuts the curve of the amounts saved out of the given income corresponding to different rates of interest (Keynes 1936, p. 178).

However, Harrod was not satisfied with showing that Keynes's result can be obtained starting from the classical theory and added, as an afterthought in the note at the end of the letter, a restatement that enabled the classical objectivethe determination of the rate of interest- to be inferred from from the premise of identity between saving and investment:

Let $y_{1}, y_{2}$ etc. be rates of interest and $Y_{1}, Y_{2}$ etc. incomes corresponding to them ( $Y_{1}$ being derived from $y_{1}$ via marginal efficiency of cap. and the multiplier). For each value of $Y$ draw classical supply curves, of which each curve shows amount of saving corresponding to various values of $y$ at a given level of $Y$. Then according to you it will be found that the value of $y$ at which the curve appropriate to income $Y_{r}$ intersects the demand curve is in fact $y_{r}$, where $y_{r}$ represents any given rate of interest whatever. The so called supply curve in the passage from your letter which I have quoted is the locus of points on the classical supply curves for that value of $y$ corresponding to the level of income on the assumption of which each was drawn (Harrod to Keynes, August 30, 1935, in Keynes 1973, pp. 556-57).

The causal relationship is inverted. Instead of starting from a given rate of 
interest and the associated supply curve at the corresponding level of income, Harrod "finds" the rate of interest corresponding to the appropriate income curve. Like the classics, Harrod takes a given level of income, so that the saving function only depends on the remaining variable, the rate of interest. If the marginal efficiency of capital is also taken as given, the investment curve can be represented as a function of the rate of interest only. The representation is actually flattened onto a surface, the saving and investment curves intersect, and the rate of interest can be determined.

That Harrod could draw both causal implication s derives from the fact that his description of the diagram does not explicitly account for shifts in the curves. On both occasions he only mentions the family of supply curves and one demand curve. ${ }^{8}$ In these conditions, given income (i.e., given a supply curve), the rate of interest is fixed accordingly while, on the other hand, given the rate of interest, the corresponding supply curve (i.e., the appropriate level of income) is uniquely determined. But this brings us back to the point Keynes and Harrod had been discussing throughout the correspondence. Harrod interpreted the level of income as a ceteris paribus clause which, if satisfied, would make the classical theory consistent on its own premises. Keynes insisted instead that one can "only invent a meaning for the classical ideas, if one assumes that income and employment cannot change" (letter to Harrod of August 14, in Keynes 1973, p. 541). Harrod's construction, opportunely modified, enabled Keynes to express this point diagrammatically. He thus added a second investment curve representing a displacement of the original schedule as a consequence of, for instance, a change in the marginal efficiency of capital. In analyzing the consequence of the displacement, he inverted once again the causal relationships in Harrod's second version, and concluded that unless the rate of interest is determined by some factor extraneous to the classical theory, the position is entirely indeterminate (Keynes to Harrod, September 10, 1935, in Keynes 1973, pp. 557-59, and Keynes 1936, pp. 180-83).

Although the diagram Keynes sent to Harrod was certainly derived from Harrod's verbal description, Keynes inverted Harrod's original causal structure, he modified Harrod's construction by introducing an additional demand curve representing a shift in the original schedule, and he used the whole set-up to argue against Harrod's defense of the classical theory. Only one concept passed intact through Keynes's re-interpretation-namely, the notion of the family of supply curves.

\section{FACTS AND INTERPRETATIONS}

An accurate examination of the surviving documents and of the general condition in which these were preserved, kept and arranged, of the author's style, of the context in which the events took place, and of Harrod's and Keynes's purposes in elaborating and using Harrod's construction, all seem to contradict Harrod's later statement attributing to himself the actual drawing of the diagram.

\footnotetext{
${ }^{8}$ This, of course, is a fundamental difference between Harrod's construction and Keynes's diagram, which adds further weight to O'Donnell's argument.
} 
The case itself is only a minor one in the history of economic thought. Nevertheless, it teaches an important lesson about the weight to be attributed to different documents. Where there is contradictory evidence, the contemporary documents should be given priority over asynchronous sources (unless, of course, there are specific reasons for thinking that the contemporary evidence is biased). O'Donnell rightly pointed out that later recollections based on memory are fallible, as memory fades with time. This, however, is not the major problem here, as Harrod wrote the Life after having reread the relevant correspondence. 9 The flow of time does not simply involve the decay of memory, but also affects recollections in more subtle ways. Events of the past are not something totally extraneous to the narrator's experience, but affect his or her interpretation of the facts. Within a few years one finds that expectations are disappointed, hopes betrayed, pessimism may be replaced by optimism (or vice versa), the economic situation changes, new theoretical perspectives are opened up and others are discarded, qualifications are added to older approaches, practical problems change, etc. Facts are thus seen in a new light, which may induce shifts in emphasis from one aspect to another that did not seem relevant in the first place or make apparent new connections which could not be seen before.

This seems to be what happened in this case. At the end of the exchange with Keynes, Harrod had realized that his attempt to induce his friend to renounce, or to soften, his line of attack was doomed to failure. ${ }^{10}$ By October 7,1935 , he knew that the only result he had obtained was to have the "most offending passages" moved to an Appendix in The General Theory. He could certainly not interpret the inclusion of the diagram as a success, as Keynes had modified and reinterpreted it, and used it against Harrod himself.

Nevertheless, Harrod remained consistent with his interpretation, which he refined and expounded after the publication of the General Theory in a paper on "Mr. Keynes and Traditional Theory," in which he argued that Keynes's theory does not represent a revolution in economics (which lay instead in economic dynamics, the foundations of which were set out by Harrod himself in The Trade Cycle, published in 1936, a few months after Keynes's book) but a rearrangement of the pieces to be found in the traditional theory (Harrod 1937; Besomi 1997 elaborates).

Harrod's fear that Keynes's book would not be understood by "those who are still in [Marshall's system of thought]"11 was disproved by the success of Keynes's theory. By the time Harrod was writing the Life of John Maynard Keynes, Keynes's doctrines were gaining large acceptance by both the academy and the public. When Harrod was drafting the relevant chapter in his biography and reread his 1935 correspondence with Keynes, the situation had radically

\footnotetext{
${ }^{9}$ Harrod also confirmed this in a letter to Hawtrey dated June 7, 1951.

${ }^{10}$ Harrod admitted defeat, but attributed it to the "confusion" due to Keynes's "failure to think [himself] back into the system of thought [he had] abandoned" (Harrod to Keynes, September 20, 1935, in Keynes 1973, p. 651). This interpretation is repeated in the Life of Keynes (Harrod 1951, p. 453).

${ }^{11}$ Letter to Keynes of September 20, 1935, in Keynes (1973, p. 561; see also p. 534). Harrod also took up the point in correspondence with Robertson (October 7, and November 15, 1935) and Kaldor (October 10, 1935).
} 
altered and he could look at these materials in a new light. He could hardly deny defeat on his "main endeavour" to "mitigate [Keynes's] attack on the 'classical' school" but, on the other hand, having exerted some influence on the most influential book of the first half of the twentieth century in the form of "a diagram purporting to reconcile the classical theory with [Keynes's] theory," he could legitimately claim some form of success.

Harrod's attribution of the diagram to himself in a letter to Hawtrey, dated June 19, 1951, does not add further weight to the statement in the biography of Keynes, as it is not independent of the latter. The exchange with Hawtrey, in fact, concerned Harrod's interpretation of Keynes's theory of interest as formulated in the Life. The diagram was first mentioned by Hawtrey, who argued that it proves that liquidity preference is not the sole determinant of the rate of interest (Hawtrey to Harrod, June 15, 1951). Harrod's statement that he "was [himself] responsible for the diagram on page 180" had the rhetorical function of killing Hawtrey's argument, rather than adding anything to it. Harrod specified, in fact, that the diagram "was an attempt to demonstrate to Maynard that his theories were not quite so out of line with the classical position as he supposed," but did not elaborate further (Harrod to Hawtrey, June 19, 1951).

Taken out of context, Harrod's claim induces readers to think that he actually drew the diagram and passed it on to Keynes, while contemporary evidence strongly suggests instead that he only supplied a verbal construction that was re-interpreted by Keynes, elaborated in the form of a diagram, and used for an entirely different purpose. This is not to claim a "conspiracy theory." Even if Harrod allowed himself the petty satisfaction of overemphasizing his own contribution to the General Theory, he was fully fair in recognizing that he failed on his "main endeavour," of convincing Keynes that his new views could be reconciled with the traditional theory. And he intentionally bequeathed to us, with the documents enabling historians of thought to assess with a reasonable degree of confidence, the course of events and the evolution of their interpretation, not only by the protagonists themselves but also their later readers.

\section{REFERENCES}

Ahiakpor, James. 1999. "The Genesis of the Only Diagram In the General Theory: A Comment." Journal of the History of Economic Thought 21 (March): 39-41.

Besomi, Daniele. 1997. "Roy Harrod and Traditional Theory." The European Journal of the History of Economic Thought 4 (Spring): 92-115.

Harrod, Roy F. 1936. The Trade Cycle: An Essay. Oxford: Clarendon.

- 1937. "Mr. Keynes and Traditional Theory." Econometrica 5 (January): 74-86.

- 1951. The Life of John Maynard Keynes. London: Macmillan.

Keynes, John Maynard. 1936. The General Theory of Employment, Interest and Money. London, Macmillan. Cited from the reprint as Vol. VII of The Collected Writings of John Maynard Keynes. London: Macmillan.

- 1973. The General Theory and After, Part I: Preparation, vol. XIII of The Collected Writings of John Maynard Keynes. London: Macmillan.

Marget, Arthur W. 1942. The Theory of Prices: A Re-Examination of the Central Problems of Monetary Theory, vol. II. New York: Prentice-Hall.

O'Donnell, Rod. 1999a. "The Genesis of the Only Diagram In the General Theory." Journal of the History of Economic Thought 21 (March): 27-37. 
1999b. "On Reading and Arguing: A Reply to Ahiakpor." Journal of the History of Economic Thought 21 (March): 43-51.

Young, Warren. 1987. Interpreting Mr. Keynes: The IS-LM Enigma. London: Polity Press.

\section{Unpublished Documents}

DHR indicates the Robertson Papers, Trinity College, Cambridge; FHK abbreviates the Knight Papers, University of Chicago Library; HMA abbreviates the Macmillan papers, British Library, London; HP indicates the Harrod Papers, Chiba University of Commerce, Ichikawa, Japan; HTRY indicates the Hawtrey Papers, Churchill College, Cambridge; JMK abbreviates the Keynes Papers, King's College, Cambridge; JVR indicates the Joan Robinson Papers, King's College, Cambridge; NKP abbreviates the Kaldor Papers, King's College, Cambridge.

Roy F. Harrod to D. H. Robertson, September 3, 1932, in DHR C18/7 (1-5).

Roy F. Harrod to J. V. Robinson, July 1, 1933, in JVR vii/191/9-10.

Roy F. Harrod to D. H. Robertson, October 7, 1935, DHR C3/2 (3).

Roy F. Harrod to N. Kaldor, October 10, 1935, in NKP NK/3/97/2-3.

Roy F. Harrod to D. H. Robertson, November 11, 1935, in HP IV-990-1069d/30.

Roy F. Harrod to D. H. Robertson, November 15, 1935, in DHR 3/2 (5-6).

Roy F. Harrod, "Mr. Keynes and Traditional Theory," second draft, in JMK GTE 2/2/41.

Roy F. Harrod to F. H. Knight, July 7, 1937, in FHK B60 F7, 106.

Untitled note describing the correspondence relating to Harrod's discovery of the marginal revenue curve, May 8, 1945, in HP IV-963-973.

Roy F. Harrod to H. Macmillan, April 21, 1948, in HMA M46.

Roy F. Harrod to R. G. Hawtrey, June 7, 1951, in HTRY 10/49. The relevant passages are cited in Young 1987, pp. 136-7.

Roy F. Harrod to R. G. Hawtrey, June 19, 1951, in HTRY 10/49. The relevant passages are cited in Young 1987, pp. 136-37.

Ralph G. Hawtrey to R. F. Harrod, June 15, 1951, cc in HTRY 10/49. The relevant passages are cited in Young 1987, pp. 134-35. 